\title{
Factors Affecting Use of Tobacco among Higher Secondary Students of Kalimati, Kathmandu
}

\author{
Mamata Pradhan $^{1}$, Basanti Pokharel ${ }^{2}$, Anisha Khadgi ${ }^{3}$ \\ ${ }^{1}$ Associate Professor, Asian College for Advance Studies, Satdobato, Lalitpur, Nepal \\ ${ }^{2}$ Lecturer, Asian College for Advance Studies, Satdobato, Lalitpur, Nepal \\ ${ }^{3}$ Registered Nurse in Rajdhani Hospital Pvt. Ltd, Balkhu, Kathmandu
}

Corresponding Author: Mamata Pradhan

\begin{abstract}
Background: Tobacco product are products made entirely or partly of leaf tobacco as raw material, which are intended to be smoked, sucked, chewed, or snuffed. Tobacco use, among the adolescents is a growing public health problem the world has ever faced. More than 7 million deaths occur from tobacco use every day. Literature has shown that the prevalence of the tobacco uses was high among adolescents.

Methodology: A cross-sectional descriptive study design was used.150 respondents were taken as sample size. Probability sampling technique and self- administered questionnaire modified from GYTS, Version 2011 was used as a research instruments. Analysis was done using SPSS version 16.

Findings: The study revealed that maximum $57.3 \%$ were male, majority $71.3 \%$ were from nuclear family, more than fifty $62.7 \%$ respondent's family uses tobacco products and majority $75.8 \%$ tobacco is used by the respondent's father. Majority $73.3 \%$ uses the hookah, more than half $64 \%$ gets tobacco from shop, and almost half $46.7 \%$ initiated tobacco product as experiment/curiosity and majority $74.7 \%$ uses in café. There is statically association found on frequency of tobacco used by the respondents with sex, residence of the respondent, time spend by the parents and initiated age of the tobacco. Greater strength of association on sex and initiated age of the tobacco use where lower strength of association on residence of the respondents and time spend by family.

Conclusion: About 15-20\% of each higher secondary school students involve on the use of tobacco products. Gender, living place, time spend by the parents, initiated age of tobacco use, increase café cultural, easy availability and accessibility were the common factors for the use of tobacco among higher secondary students. So buying and selling tobacco products everywhere must be prohibited and adolescents should be restricted to use tobacco products in café or public places.
\end{abstract}

Keywords: Tobacco, Higher Secondary Students, Factors

\section{INTRODUCTION}

Tobacco products are products made entirely or partly of leaf tobacco as raw material, which are intended to be smoked, sucked, chewed, or snuffed. All contain the highly addictive psychoactive ingredient, nicotine (WHO, 2017). According to the Surya Private Limited, the Nepal produces approximately 2.20 million kilogram of cigarettes tobacco. In Nepal, both the smoke and smokeless forms of tobacco are manufactured and available.
The smoke tobaccos which are manufacture and available in Nepal are surya, khukuri, pilot, surya light, shikhar. Not only that marlbolo, black, cigar, vape, is also available in Nepal.The smokeless form of tobacco manufactured and available in Nepal are gutkha, pan masala, sudha plus, current plus, pan gandha, pan parag, super like etc. The tobacco has adverse effect in health at any ages. According to the WHO report on global tobacco epidemic (2017), the current tobacco user among adolescent 
Mamata Pradhan et.al. Factors affecting use of tobacco among higher secondary students of Kalimati, Kathmandu.

male is $9.5 \%$, female is $4.8 \%$ whereas use of current smokeless tobacco among male is $19.7 \%$ and female is $12.9 \%$.

The tobacco epidemic is one of the biggest public health problems the world has ever faced. More than 7 million deaths occur from tobacco use every year. This figure is predicted to grow more than 8 million a year by 2030 without intensified action (Uprety, Regmi, \& Lamichhane, 2017).

Major consequences of smoking are not manifested until three to four decades after the onset of persistent smoking. The prolong use of tobacco causes the noncommunicable disease such as cancer, lung disease. In U.S nearly 40 million adults still smoke cigarettes while 4.7 million middle and high school students use at least one type of tobacco product electronic cigarettes (CDC, 2017).

A study done in Bangladesh describes that the associated factors to initiate tobacco use is due to peer pressure while the prevalence rate of tobacco smoking is $68.8 \%$ in male and $19.56 \%$ is female (Sahadat et al., 2017).Another study done in Bhopal city of India shows that the associated factor to initiate tobacco use is experimental/curiosity which is $55.2 \%$ (Bathamet., 2016). Similarly another study conducted by (Chezhian, 2015) in India found that the factors influencing tobacco use was due to surrounding influence $44 \%$, stress $42 \%$ and fun $40 \%$.

In Nepal, the prevalence of tobacco smoking among persons 15 years and older is $11 \%$ in female and $37 \%$ in male in 2016 . The percent of female tobacco smokers decreased from $26 \%$ while the male smokers have increased from $36 \%$ and the total of $16.2 \%$ youth and $17.8 \%$ adults use smokeless tobacco in Nepal (Uprety, Regmi, \& Lamichhae, 2017).

\section{MATERIALS AND METHODS}

This was a cross-sectional descriptive school based study conducted in private higher secondary school to assess the factors affecting use of tobacco among higher secondary students.

\section{Study Population}

This study has included only the tobacco users of grade 11 and 12 of private higher secondary schools of Kalimati, Kathmandu.

\section{Study Area}

Private higher secondary school of Kalimati ward no.13. Kalimati area is one of the busy area which lies inside the Kathmandu Metropolitan City. There are 14 wards inside the Kathmandu Metropolitan City.

\section{Sample Size}

150 student of grade 11 and grade 12 .

\section{Inclusion criteria:}

This study was done among the smoker students of grade 11 and grade 12 of selected private schools of Kalimati ward no 13.

Students who were interested to participate in the study.

\section{Exclusion criteria:}

Those who were nonsmoker.

Those students who were not interested to participate in the study.

Those students who were absent on the day of data collection.

\section{Data Collection Tools and Technique}

The data was collected by using the semi-structured self- administered questionnaire modified from Global Youth Tobacco Survey of version 2011.

\section{Ethical Consideration}

- The research was conducted only after the approval from the research committee of Asian College for Advance Studies.

- Verbal and written consent was taken from the respected school prior to data collection and verbal consent was taken from the respondents. 
Mamata Pradhan et.al. Factors affecting use of tobacco among higher secondary students of Kalimati, Kathmandu.

- The objectives of the study were clearly informed to the respondents.

- The confidentiality of the data was maintained strictly.

- No any feelings, cultural and ethical values and norms were harmed during the study.

Analysis of data: SPSS software was used to analyze the collected data according to the objectives and data was presented in frequency percentage table.

Period of data collection: 2018 February $27^{\text {th }}$ to March $14^{\text {th. }}$

\section{RESULTS}

The study revealed that at out of 150 respondents, majority $122(81.3 \%)$ lies in the age group of $15-18$ years and $28(18.7 \%)$ lies in the age group of 19-22 years, mean age was 17 years. Maximum 86(57.3\%) were male and more than half $64(42.7 \%)$ were female. All most all 94(62.7\%) were from grade 11 and more than fifty $56(37.3 \%)$ were from grade 12.One third $49(32.7 \%)$ respondent's gets pocket money less than 200 and 19(12.7\%) respondent's gets pocket money between Rs 600-800 per week. Majority 107 (71.3\%) were from nuclear family and least 6(4\%) were from extended family. More than fifty $82(54.7 \%)$ spends 68 hours with parents and less than fifty $68(45.3 \%)$ spends $1-5$ hours with the parents, mean time spend by family was 5 hours. More than half 94(62.7\%) respondent's family uses the tobacco products and almost half $56(37.3 \%)$ of the respondent's family doesn't use the tobacco products.

Out of 150 respondent, majority $114(76 \%)$ initiated between $13-17$ years and minority $13(8.7 \%)$ initiated after 18 years. Two third 100(66.7\%) are irregular user and one third $50(33.3 \%)$ are regular user. Majority 110(73.3\%) uses hookah and least $5(3.3 \%)$ uses weed. More than half respondents $96(64.0 \%)$ gets the tobacco product from shop and least $12(8.0 \%)$ gets tobacco products from the street vendor. Majority 112(74.7\%) uses tobacco product in café and least $7(4.7 \%)$ uses tobacco product in friend's home. Almost half $76(50.7 \%)$ finds very easy to get the tobacco products and least $6(4 \%)$ finds fairly difficult to get the tobacco products. All $150(100 \%)$ feels no barriers to buy tobacco products. Around fifty $70(46.7 \%)$ initiated to use tobacco product as experiment / curiosity and least $1(0.7 \%)$ initiated to use tobacco product due to loneliness.

There are statically association found between sex and frequency of use of tobacco products, between living place of the respondents and frequency of use of tobacco products, between times spend by the parents and frequency of use of tobacco products and between initiated age of tobacco use with frequency of use of tobacco products.

Table 1. Age, Sex and Grade of the respondents, $n=150$

\begin{tabular}{|l|l|l|}
\hline Age & Frequency & Percentage \\
\hline $15-18$ & 122 & 81.3 \\
\hline $19-22$ & 28 & 18.7 \\
\hline Mean age= 17.53 & & \\
\hline Sex & & \\
\hline Male & 86 & 57.3 \\
\hline Female & 64 & 42.7 \\
\hline Grade & & \\
\hline 11 & 94 & 62.7 \\
\hline 12 & 56 & 37.3 \\
\hline
\end{tabular}

Above table shows that out of 150 respondents, majority $122(81.3 \%)$ lies in the age group of $15-18$ years and $28(18.7 \%)$ lies in the age group of 19-22 years. Maximum $86(57.3 \%)$ were male and more than half $64(42.7 \%)$ were female. All most all 94(62.7\%) were from grade 11 and more than fifty 56(37.3\%) were from grade 12 .

Table 2. Pattern of Family, $n=150$

Table 2. Pattern of Family, n=150
\begin{tabular}{|l|l|l|}
\hline Variables & Frequency & Percentage \\
\hline Types of family & & \\
\hline Nuclear & 107 & 71.3 \\
\hline Joint & 37 & 24.7 \\
\hline Extended & 6 & 4.0 \\
\hline Time spend by family & & \\
\hline 1-5 hours & 68 & 45.3 \\
\hline 6-8 hours & 82 & 54.7 \\
\hline Mean=5.51 & & \\
\hline
\end{tabular}

Above table shows that out of 150 respondent, majority $107(71.3 \%)$ were from nuclear family and least $6(4 \%)$ were from extended family. More than fifty $82(54.7 \%)$ spends 6-8 hours with parents and less than 
Mamata Pradhan et.al. Factors affecting use of tobacco among higher secondary students of Kalimati, Kathmandu.

fifty $68(45.3 \%)$ spends $1-5$ hours with the parents.

Table 3. Tobacco Use Person in Family $n=150$

\begin{tabular}{|l|l|l|}
\hline Tobacco use person in family & Frequency & Percentage \\
\hline Father & 75 & 75.8 \\
\hline Mother & 7 & 7.1 \\
\hline Grandparents & 24 & 24.2 \\
\hline Brother & 3 & 3.0 \\
\hline Uncle & 7 & 7.1 \\
\hline \multicolumn{2}{|l}{} \\
*Multiple responses
\end{tabular}

Above table shows that out of 150 respondent, majority $75(75.8 \%)$ of the respondent's father uses tobacco products and least $3(3 \%)$ of the respondent's brother uses tobacco product. Table 8. Use of Tobacco by Friends.

Table 4. Type of Tobacco Use by Respondents, $n=150$

\begin{tabular}{|l|l|l|}
\hline $\begin{array}{l}\text { Types of tobacco use by } \\
\text { respondent }\end{array}$ & Frequency & Percentage \\
\hline Cigarettes & 61 & 40.7 \\
\hline Hookah & 110 & 73.3 \\
\hline Gutkha & 12 & 8.0 \\
\hline Sudha plus & 7 & 4.7 \\
\hline Weed & 5 & 3.3 \\
\hline Vape & 11 & 7.3 \\
\hline
\end{tabular}

Above table shows that out of 150 respondents, majority $110(73.3 \%)$ uses hookah and least $5(3.3 \%)$ uses weed.

Table 5. Source of Tobacco Product and Place for Tobacco Use, $n=150$

\begin{tabular}{|l|l|l|}
\hline Source of Tobacco Products & Frequency & Percentage \\
\hline Shop & 96 & 64.0 \\
\hline Street Vender & 12 & 8.0 \\
\hline Friends & 42 & 28.0 \\
\hline Place for Tobacco use & & \\
\hline Home & 27 & 18.0 \\
\hline Public Places & 4 & 2.7 \\
\hline Cafe & 112 & 74.7 \\
\hline Friend's Home & 7 & 4.7 \\
\hline
\end{tabular}

Above table shows that out of 150 respondents, $96(64.0 \%)$ gets the tobacco product from shop and least $12(8.0 \%)$ gets tobacco products from the street vendor and majority $112(74.7 \%)$ uses tobacco product in café and least $7(4.7 \%)$ uses tobacco product in friend's home.

Table 6. Accessibility of the Tobacco Product, $n=150$

\begin{tabular}{|l|l|l|}
\hline Accessibility of Tobacco Product & Frequency & Percentage \\
\hline Very Difficult & 20 & 13.3 \\
\hline Fairly Difficult & 6 & 4.0 \\
\hline Fairly Easy & 48 & 32.0 \\
\hline Very Easy & 76 & 50.7 \\
\hline
\end{tabular}

Above table shows that out of 150 respondents, almost half $76(50.7 \%)$ finds very easy to get the tobacco products and least $6(4 \%)$ finds fairly difficult to get the tobacco products

Table 7. Initiation Factor for Tobacco Use $\quad \mathbf{n}=\mathbf{1 5 0}$

\begin{tabular}{|l|l|l|}
\hline Initiation Factor for Tobacco Use & Frequency & Percentage \\
\hline Per Pressure & 33 & 22.0 \\
\hline Experiment/ Curiosity & 70 & 46.7 \\
\hline Academic Failure10 & 10 & 6.7 \\
\hline Stress & 34 & 22.7 \\
\hline Fun & 15 & 10.0 \\
\hline Employment & 18 & 12.0 \\
\hline Style & 4 & 2.7 \\
\hline Loneliness & 1 & 0.7 \\
\hline \multicolumn{2}{|l}{}
\end{tabular}

Above table shows that out of 150 respondents, around fifty $70(46.7 \%)$ initiated to use tobacco product as experiment/curiosity and least $1(0.7 \%)$ initiated to use tobacco product due to loneliness.

Table 8. Factors Associated with Use of tobacco Products

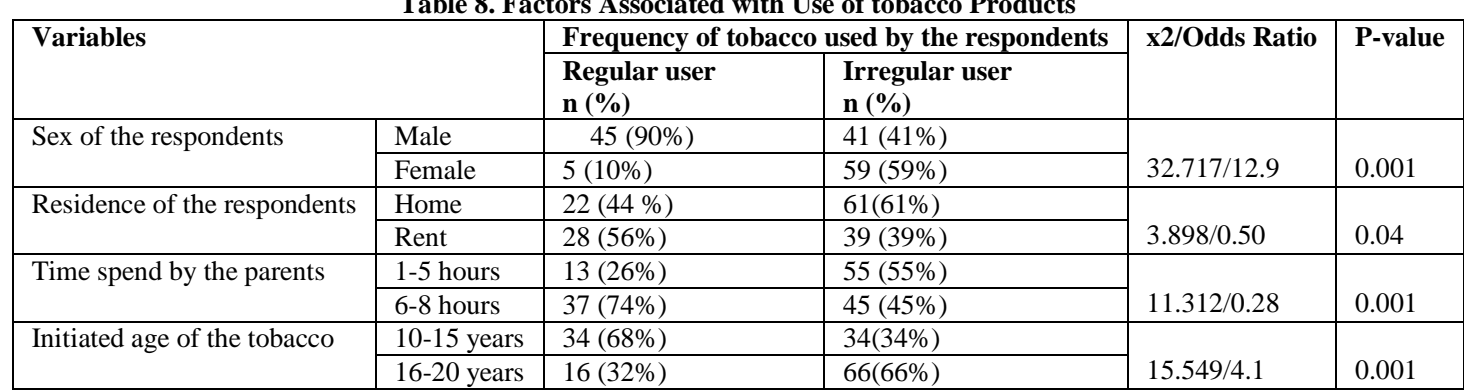

Above table shows that there are association between sex, living place of the respondents, times spend by the parents, and initiated age of tobacco with frequency of use of tobacco products, as p-value is < 0.05 . There is greater strength (odds) of association found with sex (OR-12.9) and initiated age of the tobacco (OR-4.1) on frequency of tobacco used by respondents. And lower strength of association found with residence of the respondents (OR-0.50) and time spend by the parents (OR-0.28) on frequency of tobacco used by the respondents. 


\section{DISCUSSION}

The cross-sectional descriptive study was conducted to assess the factors affecting use of tobacco among higher secondary students. 150 respondents were taken as a sample. The outcome of this study shows that among total respondents, majority $122(81.3 \%)$ lies in the age group of $15-18$ years and $28(18.7 \%)$ lies in the age group of 19-22 years. The mean age of study was 17.53. More than half $86(57.3 \%)$ were male and less than half $64(42.7 \%)$ were female because male have risk taking behavior higher in compare to female. Similar findings were found in the study conducted by Shrivastava et al., 2015 where majority $80.9 \%$ were male. This shows that there is a match between age and level of education. These age groups adolescences are mostly involve in gaining new experiences. This study shows that all most all 94(62.7\%) were from grade 11 and more than fifty $56(37.3 \%)$ were from grade 12 . More than fifty $82(54.7 \%)$ were Janjati, as Janajati includes multiple castes. One third $46(30.7 \%)$ were Chettri, 18(12\%) were Brahmin and least $4(2.7 \%)$ were Muslim.

In this study, one third 49(32.7\%) participant gets pocket money less than Rs 200 , one fourth $40(26.7 \%)$ participant gets pocket money between Rs 200-300, $42(28 \%)$ participant gets pocket money between Rs 400-500 and 19(12.7\%) participant gets pocket money between Rs 600-800 per week. Although they gets less pocket money they were involved on use of tobacco products. This finding is contrast to the research conducted by Shrivastava et al., 2015 where respondent pocket money was the major source of purchasing of tobacco products i.e. $57.1 \%$ In this study, majority $107(71.3 \%)$ were from nuclear family, one fourth $37(24.7 \%)$ were from joint family and least $6(4 \%)$ were from extended family. This study shows, more than fifty $82(54.7 \%)$ spends 6-8 hours with parents and less than fifty $68(45.3 \%)$ spends $1-5$ hours with the parents. Since the respondents lives in nuclear family and does not spend maximum time with their parents it shows, they gets enough time to take tobacco products. More than half $83 \%$ $(55.3 \%)$ lives with their family, one third 31 $35(23.3 \%)$ lives in rent with their friends, $31(20.7 \%)$ lives in rent with their family, and least $1(0.7 \%)$ lives in the hostel. Similarly, more than half 94(62.7\%) participant's family uses the tobacco products and $56(37.3 \%)$ of the participant's family doesn't use the tobacco products. It shows that tobacco user in the family influences the use of tobacco products. Most $75(75.8 \%)$ of the respondent's father use tobacco products.

Present study shows, two third $100(66.7 \%)$ are irregular user and one third $50(33.3 \%)$ are regular user. Majority $114(76 \%)$ initiated between 13-17 years, $23(15.3 \%)$ initiated before 13 years and minority $13(8.7 \%)$ initiated after 18 years. The mean age of initiation is 15 years. The finding is contrast to the research conducted in the Bangladesh by Bathmat et al., 2016 where result showed that the age of initiation of tobacco use was 10 years. In this study, majority $130(86.7 \%)$ respondent friend uses the tobacco product and $20(13.3 \%)$ respondent friends don't use the tobacco product.

The current study shows that majority $110(73.3 \%)$ uses hookah less than fifty $61(40.7 \%)$ uses cigarettes, least $12(8 \%)$ uses gutkha, $12(4.7 \%)$ uses sudha plus, $11(7.3 \%)$ uses vape and $5(3.3 \%)$ uses weed. It shows increasing outgoing culture among adolescents. More than half 96(64.0\%) gets the tobacco product from shop, 42(28\%) gets the tobacco product from friends and least $12(8.0 \%)$ gets tobacco products from the street vendor. This finding is supported by the research conducted by P. Pradhan \& Kalra, 2015, where $66 \%$ of the users purchased tobacco directly from shops. In this study, half $76(50.7 \%)$ finds very easy to get the tobacco products and least $6(4 \%)$ finds fairly difficult to get the tobacco products. In this study, total respondent $(100 \%)$ stated that they feel no barriers to buy tobacco products. It shows that there is no any restriction on buying and selling 
Mamata Pradhan et.al. Factors affecting use of tobacco among higher secondary students of Kalimati, Kathmandu.

tobacco in our country. The current study shows, around half $70(46.7 \%)$ initiated to use tobacco product as experiment/curiosity, one fourth $33(22 \%)$ initiated due to peer pressure, $10(6.7 \%)$ initiated due to academic failure, $34(22.7 \%)$ initiated due to stress, $15(10 \%)$ initiated as fun, $18(12 \%)$ initiated as enjoyment, $4(2.7 \%)$ initiated as style and least $1(0.7 \%)$ initiated to use tobacco product due to loneliness. This finding is supported by research conducted by Hossain et al., 2015 where $48.3 \%$ initiated as curiosity.

In this study, majority $112(74.7 \%)$ uses tobacco product in café, 27(18\%) uses tobacco product in home, $4(2.7 \%)$ uses in public places, and least $7(4.7 \%)$ uses tobacco product in friend's home. This finding is contrast to the research conducted by P. Pradhan \& Kalra, 2015 where $36 \%$ consumed tobacco at home. As different varieties with different flavor tobacco are available in the café, so the respondent mainly uses tobacco products over there. The current finding shows that there is statistical association between sociodemographic variables with the frequency of the use of tobacco. This finding is supported by research conducted by Gaffar et al., 2013 where the result shows that there is association between the socio-demographic and tobacco smoking.

\section{CONCLUSION}

This study revealed that approximately $15-20 \%$ of the students from each higher secondary school use tobacco products. Although the respondents get pocket money less than Rs.200 per week, they still use tobacco products. The major tobacco product used by the student is hookah and the place for using the tobacco product is café. Nuclear family, less time of parents with their children, easily availability of the tobacco products, increase outgoing culture and gender are the major factors to the use tobacco products among higher secondary students. So buying and selling tobacco products everywhere must be prohibited and adolescents should be restricted to use tobacco products in café or public places.

Acknowledgement: None

Conflict of Interest: None

Source of Funding: None

Ethical Approval: Approved

\section{REFERENCES}

1. Bathma, V., Agarwal, S., Shukla, U., Bathma, V., Med, J. C., \& Health, P. (2016). Study to find factors influencing first tried tobacco use among adolescent students in Bhopal city of Madhya Pradesh , India, 3(1), 136-139.

2. Chezhian, C. (2015). Exploring Factors that Influence Smoking Initiation and Cessation among Current Smokers. Journal of Clinical and Diagnostic Research, 9(5), 6-13. https://doi.org/10.7860/JCDR/2015/12047.5 917

3. Gaffar, A. M., Alsanosy, R. M., \& Mahfouz, M. S. (2013). Sociodemographic factors associated with tobacco smoking among intermediate and secondary school students in Jazan Region of Saudi Arabia. Substance Abuse, 34(4), 381-388. https://doi.org/10.1080/08897077.2013.779 361

4. Global Youth Tobacco Survey Collaborative Group. (2012). GYTS Core Questionnaire with Optional Questions, (Version 1).

5. Hossain, A., Hossain, Q. Z., Azad-uzzaman, Q., \& Rahman, F. (2015). Factors Influencing Teenager to Initiate Smoking in South-west Bangladesh. Universal Journal of Public Health, 3(6), 241-250. https://doi.org/10.13189/ujph.2015.

6. Pradhan, P., \& Kalra, S. (2015). Factors Associated with Tobacco Use among Female Adolescent Students in Dharan Municipality of Eastern Nepal. Journal of Nepal Health Research Council, 13(3), 220225.

7. Pradhan, P. M. S., Niraula, S. R., Ghimire, A., Singh, S. B., \& Pokharel, P. K. (2013). Tobacco use and associated factors among adolescent students in Dharan, Eastern Nepal: A cross-sectional questionnaire survey. BMJ Open, 3(2). 
Mamata Pradhan et.al. Factors affecting use of tobacco among higher secondary students of Kalimati, Kathmandu.

https://doi.org/10.1136/bmjopen-2012002123

8. Shrivastava, N., Verma, N., Bhawnani, D., \& Soni, G. (2015). Prevalence of smokeless tobacco use among school going adolescent students of Raipur city Chhattisgarh state, India. International Journal of Research in Medical Sciences, 3(4), 921. https://doi.org/10.5455/23206012.ijrms2015042

9. Uprety, S., Regmi, K., \& Lamichhane, B. (2017). Herd Special Series Report June 2017 Towards Tobacco Control : World No Tobacco Day In Nepal Sudeep Uprety Kritagya Regmi Bipul Lamichhane, (June).

10. World Health Organization (2017).A definition of tobacco [2017]. Retrieved
January, $\quad$ 02, 2018, from http://www.who.int/topics/tobacco/en/

11. World Health Organization (WHO). (2017). Who Report on the Global Tobacco Epidemic, 2017. World Health Organization. Retrieved January,02,2018,from http://apps.who.int/iris/bitstream/10665/255 874/1/9789241512824-eng.pdf?ua=1\&ua=1

How to cite this article: Pradhan M, Pokharel B, Khadgi A. Factors affecting use of tobacco among higher secondary students of Kalimati, Kathmandu. Int J Health Sci Res. 2021; 11(6):381-387. DOI: https://doi.org/10.52403/ ijhsr.20210657 